\title{
Mental health services in Kumasi, Ghana
}

\author{
Richard Laugharne and Tom Burns
}

During March 1998 we had the privilege of visiting the mental health services in Kumasi, Ghana at the invitation of Dr Yaw Osei, Senior Lecturer at the Department of Behavioural Sciences, School of Medical Sciences, University of Science and Technology.

\section{Fistory of peychiatry in Ghana}

The first asylum for mentally ill patients was opened in 1888 at Accra, the capital city on the south coast of Ghana (then the Gold Coast). By 1904 there were 104 patients at the asylum and in 1907 the asylum was moved to its present location. The hospital was intended to care for a maximum of 122 patients, but two years later there were 275 in-patients (Forster, 1962). In 1929 the first psychiatrist was appointed, but was only in post for a short time. In $1951 \mathrm{Dr}$ Forster, a Gambian psychiatrist trained in the UK, was appointed. He was the first African psychiatrist in sub-Saharan Africa and remained at Accra until 1970. By 1960 the asylum housed 1700 patients and another hospital was opened nearby at Pantang in 1975. Today the services of Accra are still over-stretched. There are 800 beds in Accra Hospital, but up to 1500 patients. There are no long-term facilities in the community and the doctors describe many patients as being "dumped" in the hospital from all over the country as their families refuse to care for them.

The hospital at Ankoful, near Cape Coast, was opened in 1966 with 500 beds and has provided care in the south-western part of Ghana. In 1982 Dr Yaw Osei was invited to start a Department of Behavioural Sciences by the dean of the medical school at the University of Science and Technology. Kumasi in central Ghana. A psychiatric clinic was set up and an in-patient unit followed in 1989.

\section{Mental health services in Kumasi}

Kumasi, the capital of the Ashanti region has a population of 1.5 million people - Ghana's total population is 16 million. It is the only formal state psychiatric service in inland Ghana, the north of the country has none.

The psychiatric unit at the Komfo Anokye Teaching Hospital consists of an 11-bed inpatient unit and an out-patient unit consisting of three rooms and a small secretarial area. An outdoor courtyard is used for patient and carer meetings. Conditions are sparse but clean, with fans for patient's comfort. The maximum stay at the in-patient facility tends to be two months. All patients must have a relative staying with them day and night, the relative must also provide food for the patient.

Dr Osei, Senior Lecturer and Consultant Psychiatrist, trained as a child psychiatrist in Germany and is head of the unit. An educational psychologist and an ethicist/psychotherapist are lecturers at the university and also work as clinicians. Three junior doctors employed by the Ministry of Health and nursing staff complete the unit personnel.

The five weekday mornings are occupied by an adult new patient clinic, child clinic, ward round, follow-up clinic and educational morning. Notes are kept on hospital records and new patients are numbered consecutively during each year. There is a limited list of drugs available free of charge: chlorpromazine, haloperidol, trifluoperazine, phenobarbitone, amitriptyline, imipramine, diazepam and promethazine. Fluphenazine, the only depot antipsychotic available, is sometimes given free of charge in emergencies. Other drugs such as carbamazapine and phenytoin are available from private chemists if the patient can afford them.

Establishing a psychiatric service was not easy. Dr Osei's first clinic was in his car, as he had no room to see patients. He named the clinic the 'Headache Clinic', because mental illness is taboo in Ashanti culture. Dr Osei attempted some satellite clinics in the surrounding area, but these depended upon enthusiastic personnel who subsequently left. The medical school has also demonstrated ambivalence towards psychiatry but the current dean is committed to the department, recognising that people with mental illness are especially stigmatised in Ghanaian society. The medical school is now 
recognised by the General Medical Council in the UK.

\section{Clinical work}

The clinic at Kumasi sees approximately 90-120 patients per week, 10 of whom will be new patients. There is a wide range of diagnoses. Psychotic illnesses predominate on the inpatient unit and the most common diagnoses in the out-patient unit are psychoses, depression, somatisation disorder and epilepsy.

A meeting with patients and relatives takes place in the courtyard each Wednesday to facilitate their involvement. Patients quite frequently miss follow-up appointments, a matter discussed at the patients and relatives meeting that $R$. L. attended. The reasons identified were: side-effects of drugs leading to lethargy and lack of motivation; the expense (a patient lived $200 \mathrm{~km}$ away and was unemployed); the clinic starting too late at $9.00 \mathrm{am}$; one patient tried traditional healers for two years after initial diagnosis, but nothing else was effective until he returned to the clinic; and one patient became fed up with waiting to see the doctor. Patient education has been shown in the clinic to improve patient attendance.

Many patients with epilepsy are seen in the clinic as there is no neurologist at the hospital. A physician sends patients to the psychiatrist. The following case is illustrative.

A patient with epilepsy was prescribed phenobarbitone $60 \mathrm{mg}$ twice a day (free of charge) and carbamazapine $1000 \mathrm{mg}$ daily in divided doses. On closer questioning the patient informed me that 30 days of carbamazapine cost 70000 cidies. The patient earned about 6000 cidies per month and was not taking any of these tablets. The phenobarbitone dose was increased to $60 \mathrm{mg}$ three times a day.

\section{Role of relatives}

Most patients attending the clinic are accompanied by relatives who are expected to take responsibility for the patient's care. All inpatients must have a relative sleeping at the hospital with them. If there are no beds the patient is sent home with the relative, and they must return if a bed is available.

\section{Other clinical services}

The Cheshire Home houses 50 patients for an average length of stay of 14 months offering occupational, work and art therapy. It was opened in 1987 and it is a voluntary organisation supported by the Catholic Church. Referrals are directly from relatives, from pastors or from hospitals. Most patients suffer from psychotic illnesses and are on antipsychotic medication and relatives must remain involved and pay a nominal fee. All patients learn a trade before they leave and outreach workers monitor them for up to three years after discharge. There is also a drug and alcohol education service at the house and some patients with substance misuse problems are admitted. The main occupations are sewing, making shoes and wreaths and art therapy.

A separate community psychiatric clinic supported by the World Health Organization was established in 1975 . This clinic sees up to 800 new patients each year and is able to visit some patients at home. There is also a private clinic and in-patient unit in Kumasi run by a psychiatrist who works with the medical school as a part-time lecturer facilitating some coordination of care between services.

\section{Cultural alternatives to mental health services}

The people of Ghana have a strong tradition of religious observance and cultural life revolves around religious rituals. This is still the case since most Ghanaians have converted to Christianity. As a result, if a person becomes mentally ill they often turn to the Church as the first place of help. A conventional minister (Roman Catholic. Anglican. Presbyterian. Methodist or Baptist) as well as helping spiritually, might also suggest that the patient seeks psychiatric help. Pentecostal churches (of which there are many independent churches and pastors) might not encourage psychiatric referral, but suggest demonic or spiritual oppression as the sole source of the problems. Some 'prayer houses' take in people with mental illness and often use physical restraints to deal with them. Spiritual churches, a mixture of Christian, traditional and animistic beliefs, also do this. These churches can be mildly antagonistic to Western medical models.

\section{The visit}

While in Kumasi we had extensive discussions with Dr Osei and the clinical staff at Komfo Anokye Teaching Hospital, participated in the ward rounds and clinics and were given the chance to see patients and be actively involved in their treatment. We visited the community psychiatric nurse and private clinics in Kumasi and were able to see the range of services in the town. Our meeting with the dean of the medical school, Professor Brobby, opened up new possibilities for collaboration between our medical schools. We also had the chance to visit the psychiatric hospitals at Accra and Ankoful and 
compare and contrast mental health care at the three sites as well as talk to staff.

\section{Possibilities for collaboration}

The World Health Organization has published an agenda for research in mental health in the developing world (Desjarlais et al, 1995). They suggest six principles:

(a) Ethnographical studies should precede epidemiological or intervention studies.

(b) Interventions should be community-based using local services and resources.

(c) Researchers should be local.

(d) The cultural relevance of new treatments should be assessed.

(e) Awareness of ethical issues is essential.

(f) Research should be interdisciplinary.

They also suggest that the following areas are particularly in need of research development:

(a) Culturally-informed databases.

(b) Mental health service evaluation.

(c) Violence.

(d) Women's mental health

(e) Prevention.

We shall be looking to collaborate with the University of Science and Technology in Kumasi in the areas of mental health service evaluation following these World Health Organization principles.

\section{Acknowledgements}

We would like to thank all staff at the School of Medical Sciences, University of Science and Technology Kumasi for welcoming us to their unit. We especially thank Dr Yaw Osei. Father John Appiah-Poku and Ms Emma Mensah. We also thank Dr Victor Doku for help in guiding us to the appropriate information.

\section{References}

DESJARIAIS, R., EISENBERG, L.. GOOD, B., et al (1995) World Mental Health. New York: Oxford University Press.

FOSTER. E. B. (1962) The theory and practice of psychiatry in Ghana. American Joumal of Psychotherapy. 1. 7-51.

* Richard Laugharne, Honorary Senior Lecturer. and Tom Burns, Head of Section of Community Psychiatry. St George's Hospital Medical School, Cranmer Terrace, London SW17 ORE

*Correspondence

\section{Mental Health of Ethnic Minorities: GASKEI An Annotated Bibliography}

\section{Dinesh Bhugra}

This book will an invaluable source for mental health professionals who come into contact with minority ethnic groups in their clinical and research practice. It provides an annotated bibliography of recent papers which describe research on mental health of minority ethnic groups in the UK. Collected from a number of resources, these papers highlight the current status of the research. They will prove useful to clinicians and researchers alike, informing clinical practice and helping formulate research ideas. This volume will be of use to mental health professionals as well as those who are interested in the field of crosscultural psychiatry.

July 1999, Paperback, ISBN 190124231 5, £25.00

Avallable from Book Sales, Royal College of Psychiatrists, 17 Belgrave Square, London SWIX 8PG $\mathrm{Tel}+44$ (0) 1712352351 (extension 146), Fex +44 (0) 1712451231 http://www.rcpsych.2c.uk 